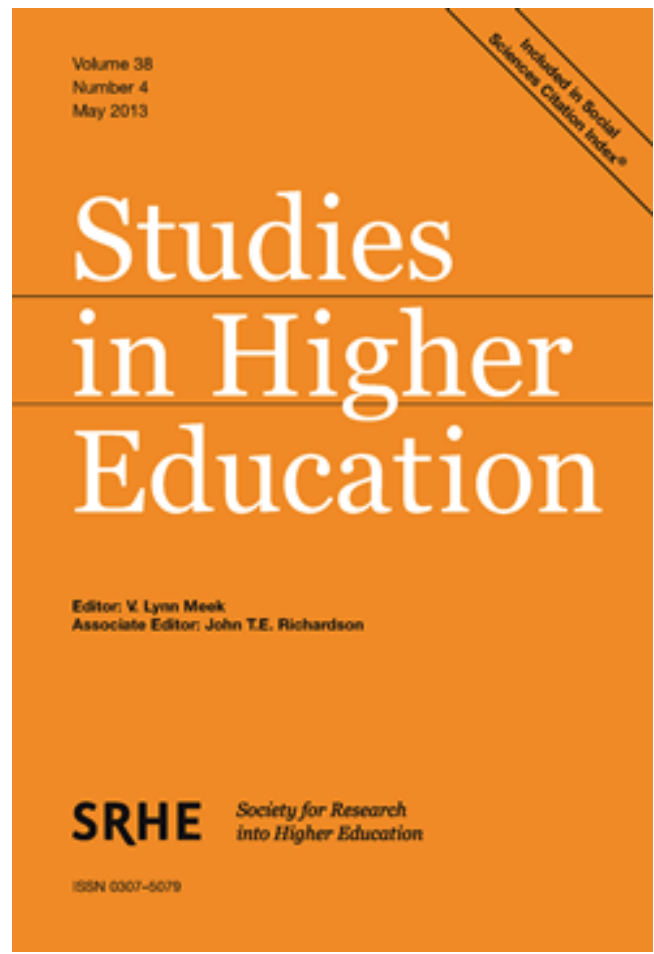

\title{
Exploring Academic Dishonesty in the Middle East: A Qualitative Analysis of Students' Perceptions
}

\begin{tabular}{|r|l|}
\hline Journal: & Studies in Higher Education \\
\hline Manuscript ID & CSHE-2018-0777.R2 \\
\hline Manuscript Type: & Article \\
\hline Keywords: & $\begin{array}{l}\text { Fahlawi, Shame, Academic dishonesty, Arab culture, global education } \\
\text { markets }\end{array}$ \\
\hline
\end{tabular}

\section{SCHOLARONE ${ }^{\text {th }}$ \\ Manuscripts}

Citation:

Saladin Aljurf, Linzi J. Kemp \& Paul Williams (2019) Exploring academic dishonesty in the Middle East: a qualitative analysis of students' perceptions, Studies in Higher Education, DOI:

$10.1080 / 03075079.2018 .1564262$

This is an Accepted Manuscript of an article published by Taylor \& Francis in Studies in Higher Education on January 8, 2019, available online: https:// www.tandfonline.com/doi/abs/10.1080/03075079.2018.1564262 


\title{
Exploring Academic Dishonesty in the Middle East:
}

\section{A Qualitative Analysis of Students' Perceptions}

\begin{abstract}
Most previous studies of academic dishonesty have been conducted in North America and Europe, and have focused on the contextual, institutional, and individual factors that influence students' propensity to cheat. While such studies offer useful background and structure to this endemic problem, this study aimed to gain deeper insights into student perceptions of academic dishonesty in a multi-cultural context. Our study sample was sourced from a large private university based in the United Arab Emirates, in which there is a culturally diverse mix of national and international students (Arab and non-Arab). From our data, while a number of student perceptions were similar to those reported in other studies, several new socio-cultural themes emerged. In particular, Arab students perceived: peer student obligations; patriarchal pressure; shame avoidance; and a Fahlawi mind-set, as being influential on their academic dishonesty attitudes and behaviours.

[Fahlawi - derives from 'fellahin' or quick-witted individual. This Arab cultural term references a person with a highly adaptive attitude and an ability to achieve things with minimal effort (Mayfield 2014; Beit-Hallahmi 1972)].
\end{abstract}

\section{Keywords:}

Academic dishonesty; Arab Culture; Shame; Fahlawi 


\section{Background}

The rapid internationalisation of Higher Education (HE) in recent years has created opportunities and challenges for universities. One such challenge is the increase in academic dishonesty amongst students, which has become a widespread and global phenomenon (Bretag 2016; Simkin and McLeod 2009). Most previous studies into academic dishonesty amongst students have been conducted in the United States of America (USA), Europe and Australia (Cinali 2016; Payan, Reardon and McCorckle 2010). While numerous reports of cheating incidents have been reported globally, there remains a distinct lack of international studies on academic dishonesty in the ethics and educational literature (Williams et al. 2014; Chapman and Lupton 2004).

Understanding academic dishonesty becomes far more complex in international contexts, as individual and contextual factors are also confounded by socio-cultural influences (Payan, Reardon and McCorckle 2010; Chapman and Lupton 2004). There are some studies that have examined the academic dishonesty phenomenon in mixed-culture contexts (Ives et al. 2017; McCabe, Feghali and Abdallah 2008; Rawwas, Al-Khatib and Vitell 2004). We suspected that some of the Western academic frameworks would be difficult to apply because of the cultural complexity in this research environment. Culture has been shown to be an important influence on broader ethical behaviour (Chapman and Lupton 2004; Ralston, Giacalone and Terpstra, 1994), and we expected it would play a major influence on students' attitudes and behaviours towards academic integrity in our study. The purpose of this research therefore, was to examine the cultural, and other social influences, on students' attitudes towards academic dishonesty. The context of our study is the United Arab Emirates (UAE), as part of the broader Middle East region, where there is a growing interest into understanding the unethical behaviours of students (Williams et al. 2014; Feghali and Abdallah 2008). 


\section{Literature Review}

We firstly, define academic dishonesty and overview literature on the topic, including studies on the reasons for students' propensity towards cheating behaviours. Then, we review literature that considers the need for academic integrity in HE.

\section{Studies on academic dishonesty}

Academic dishonesty is defined as the deliberate behaviour or action that results in misrepresentation of academic materials, or by taking credit or recognition for academic work (UNESCO 2003). There has been a wealth of academic research investigating the reasons behind academic dishonesty in the USA, Europe and Australia. In particular, the work of McCabe and Trevino (1997; 1993) in North America, and Bretag (2016) in Australia, have stimulated a number of studies that identified the main institutional and individual factors that drives academic dishonesty. While results from these studies vary, the common theme is that large numbers of students have participated in cheating, or have been exposed to other students who have cheated. Detected incidents of academic dishonesty maybe however, only a small percentage of the whole problem, as it has been reported that over two-thirds of students in the USA confessed to cheating at least once during their university careers, with only a small number of those incidents detected (Szabo and Underwood, 2004; McCabe and Trevino 1993).

In the search for explanations, academics have identified a large number of individual and contextual factors that influenced students' propensity to cheat at college. Several authors have considered demographic factors such as: previous educational background; age; gender; religion; intelligence (Beasley 2010; Brown and Choong 2005; McCabe, Trevino and Butterfield 2002). Others have considered individual psychological drivers: desire for higher grades; laziness; procrastination; lack of preparation; individual personality; moral values 
(Ives et al 2017; McCabe, Butterfield and Trevino 2002). A consideration is the emphasis on Grade Point Average (GPA) as gateway to future work, whereby a poor choice of major or wrong level of course may result in low GPA, and negatively affect employment (Ives et al. 2017; Moffatt 1990). Graduates today are therefore under increasing pressure to achieve higher grades, as a precursor to 'getting ahead' through better jobs and higher salaries (Simkin and McLeod 2009). Such intense pressure to access today's highly competitive international labour market acts as a stimulus for students, and appears to be linked to academically dishonest behaviour (Ahlawat and Ahlawat 2006). The issue may go beyond school and university, because dishonesty during the education years has also been closely linked to unethical behaviour in work environments (Lawson 2004; Nonis and Swift 2001).

\section{Institutional reasons for academic dishonesty}

Universities are very keen to maintain the integrity of their qualifications and their brand reputations by tackling academic dishonesty head-on (McCabe, Feghali and Abdallah 2008). With their credibility under threat, universities have therefore, implemented many initiatives in an attempt to reduce or remove academic dishonesty from their institutions. Initiatives have included the implementation of official policies with severe penalties if students are caught; installation of technology-based detection systems; implementation of tighter assessment procedures; and adoption of honour codes (Macfarlane, Zhang and Pun, 2014; Vandehey, Diekhoff and LaBeff 2007; McCabe, Trevino and Butterfield 2002).

There are several other institutional reasons that may drive students' dishonesty, despite these university initiatives to counter such behaviours. For example, there is often a lack of awareness, understanding, and compliance to academic integrity policies amongst both students and faculty, resulting in policy enforcement issues (Gullifer and Tyson 2014; Park 2003). In addition, there is a lack of appreciation of honour codes and how they should be used (McCabe, Butterfield and Trevino 2002). Other contextual factors in the institutional 
environment increase students' propensity for academic dishonesty. Examples may include: class sizes (too large); faculty's design of assessments may be poor or inappropriate and could foster academic dishonesty; too little faculty support of students; severity of sanctions for cheating may be unclear to students (Texeira and Rocha 2010; McCabe, Trevino and Butterfield 2002).

Unfortunately, it seems that many university policies for reducing academic dishonesty do not work effectively and, despite the penalties for being caught, many students continue to be dishonest (Williams et al. 2014). Academic dishonesty among students at university has thus, become a growing, widespread and international phenomenon. McCabe, Feghali and Abdallah (2008) suggest that understanding how students think about academic integrity and what affects their decisions to engage in dishonest behaviour, may allow institutions of HE to reduce cheating incidences. From the literature review so far, it can be seen that academic dishonest behaviours among students is a complex and complicated issue, with various intertwining contextual, social and demographic factors that need to be considered.

\section{Socio-cultural influences on academic dishonesty}

While these earlier studies have contributed significantly to our understanding of some of the drivers of academic dishonesty, there remains ambiguity and uncertainty about which factors are more influential than others, and in which contexts they can be applied to improve academic integrity (McCabe, Feghali and Abdallah 2008). Despite the wealth of research into academic integrity in general, there are three research areas that have not been fully explored in the literature. First, there are relatively few studies that have focused on student perceptions of academic dishonesty (Gullifer and Tyson 2014; Simkin and McLeod 2009). Investigating student perspectives of academic dishonesty in-depth, can help discern the reasons behind why students cheat and enable prevention strategies (Gullifer and Tyson 2010; Ashworth, Bannister and Thorne 1997). Several studies have explored student 
perceptions and found that cheating perceptions are socially constructed, meaning different things to students in different social contexts. For example, researchers have found that students view plagiarism less seriously than academics, and the latter vary their interpretations depending on whether an act of plagiarism was intentionally deceptive, or just part of academic scholarship norms when paraphrasing (Gullifer and Tyson 2010; Park 2003). Others have found that despite access to university publications, on what are plagiarism behaviours, students were confused and ignorant about what they perceived plagiarism to be, and what were the conventions of appropriate citations (Gullifer and Tyson 2014; Beasley 2010; Ercegovac and Richardson, 2004). The latter authors also concluded that further moral and ethical understanding was required to heed academic integrity strategies in the now digital HE environment (Ercegovac and Richardson, 2004).

Some researchers have also investigated the role of peer students who were found to be key social influences on academic dishonesty (Carrell, Malmstrom and West 2008; Wideman 2008; McCabe, Trevino and Butterfield 2002). It was found in these studies that a social norm, supportive of cheating, was a predictor of cheating behaviour amongst peers. In another study, Ashworth, Bannister and Thorne (1997) found that peer ethics and student loyalty were key drivers of academic dishonesty behaviour. Their study, and others, have highlighted that academic dishonesty can be demonstrated through students' social conformity needs, a need not to betray their peers, and a reluctance to report others who cheated (Ashworth, Bannister and Thorne 1997; Carrell, Malmstrom and West 2008). Certainly, it appears that there are strong social influences and contextual interpretations on academic dishonesty that merit further investigation in this study.

Second, the influence of culture on academic dishonesty, has received relatively little attention from researchers (Alt and Geiger 2012; Rawwas, Al-Khatib and Vitell 2004). As academic dishonesty has become a global problem (Simkin and McLeod 2009), cultural 
factors have come more into play (Chapman and Lupton 2004; Grimes 2004). In one study, a higher prevalence of cheating was found in the Lebanon than in the USA (McCabe, Feghali and Abdallah 2008). Similarly, Diekhoff et al. (1999) compared Japanese students with a sample of North American students, finding that the former was more likely to cheat than the latter. It was concluded that Japanese students justified their behaviour, and were less deterred by the fear of punishment and social stigma, than their counterparts from the USA (Diekhoff et al. 1999). While there were similarities between the two cultures, with social stigma being a very low ranked deterrent, a fear of sanctions was ranked as highly effective in both cultures.

In another study, for one particular cultural dimension - collectivism (Hofstede 2001), students from China (a collectivist culture) were perceived to cheat more than students from the USA (an individualistic culture) (Rawlinson and Lupton 2007). In collectivist cultures it would appear that there is more tolerance towards cheating and helping others, even during exams (Kwong et al. 2010). In fact cheating was sometimes considered acceptable, and may even be encouraged in some cultures (McCrohon, M., and Nyland, B. 2018; Chapman and Lupton 2004; Magnus et al. 2002). In Pakistan, yet another collectivist culture, it was considered unethical to accuse students of cheating because of their self-respect (Rehman and Waheed 2014). Such behaviours have been identified, but researchers have yet to find out why this is considered appropriate behaviour across different cultural boundaries (Payan, Reardon and McCorckle 2010).

Other studies have found that culture can influence academic dishonesty, particularly amongst international students studying in Western Universities. McCrohon and Nyland (2016; 2018) found that the increased commoditisation of university education meant students with poor language skills were being admitted to Australian universities. Poor language skills were reported as one of the drivers of plagiarism by the Chinese students and 
the Australian academics in their study. Similarly, Bretag et al. (2018) also found that students studying in Australian universities were more prone to cheat if the students' first language was other than English. In other studies, culture has been also shown to influence academic dishonesty. For example, James, Miller and Wyckoff (2017) found that the most significant factor in plagiarism behaviours from Chinese students is their belief in Confucian, where to achieve a 'standard answer' expected by experts was the aim. Furthermore, Chinese students were more likely to cheat when observing others cheat (Tsui and Ngo, 2016). These studies, among others, suggest that there are many interesting cultural nuances and insights that merit further investigation in the academic literature. Our study offers some additional socio-cultural insights and influences on academic dishonesty in the Arab world.

\section{Socio-cultural influences on academic dishonesty in the Arab world}

The third gap in the research literature is the cultural influences on students from the Arab world and broader Middle East region (Cinali 2016; Khan and Balasubramanian 2012; Shaw 1996). This region is usually referred to as the Middle East North African region (MENA), and, as Cinali (2016, p.114) notes, "each country in the region faces different challenges in the quality of higher education.....but the field of academic integrity has not been mapped." It is contended that cheating on exams is rampant in the Arab world involving elaborate networks, advanced technology and adult approval (Buckner and Hodges 2016). While their study focused on exit exams from secondary schools in Jordan and Morocco, there is anecdotal evidence that cheating is endemic in the Arab World, in both schools and universities (Buckner and Hodges 2016).

Arab culture is generally seen as high on collectivism, masculinity, power distance and uncertainty avoidance (Hofstede 2001). In the Arab world, a collectivist orientation is prevalent where there is a tight web of kinship and family, and where relationships foster solidarity, help and support in social situations (Alt and Geiger 2012). Collectivism translates 
into student life where the social bonds are very strong and when students 'help' each other, that behaviour can transcend ethical boundaries in a western perspective (Buckner and Hodges 2016). The latter authors suggest that students know their behaviour, in helping others, to be haram (wrong), but they cannot say no to their friends. It is an operation of social capital with mutual reciprocity (Cinali 2016). In the Arab world, helping friends and family maybe a stronger social obligation that transcends ethical considerations originating through a Western lens (Buckner and Hodges 2016; Cinali 2016). To compound the problem, it has been reported that the parents of students can permit cheating to happen with implicit and explicit consent, e.g. by circulating answers to exams for relatives, or by paying for written assignments for their children (Abou-Zeid 2016; Buckner and Hodges 2016).

In Arab nations, the value of various professions such as medicine, engineering and law, mean that parents may support cheating because the 'means justify the ends' in support of a valuable future career for their children (Buckner and Hodges 2016). This justification was supported by the analysis of Egyptian students that the secondary schooling system was where academic dishonesty issues originated (Abou-Zeid 2016; Metwally 2013). In those studies, some students were helped by their parents to cheat on the admission tests to enter university (Abou-Zeid 2016; Metwally 2013). Similarly, a low command of English as a second language may also influence students' propensity to cheat, in order to attain a place at a highly esteemed university (Cinali 2016; Carroll 2009).

In addition, there may be a number of more subtle cultural influences in the MENA region caused by historical, political and ethnic diversity. Such diversity brings differences in peoples' values, beliefs and behaviours that reflect variations or possible convergence with institutional moral values, beliefs and behaviours (Al-Khatib et al. 2005). Another sociocultural influence that we explore is the concept of shame avoidance. Western cultures are more attuned with a guilt culture, which rests on the 'Achillean standard' of morality through 
individual conscience (Creighton 1990). A guilt culture is built on an internalised conviction of $\sin$ (Kaufman 2011), where the individual feels guilty breaking the social code. In contrast, Arab culture depends on shame and honour, as the arbiter of social conscience. Arab culture is considered a shame culture in which the individual is safe from sanction as long as no one knows her/his misdeed (Kaufman 2011; Mead 2003). Shame must be avoided through the individual's adherence to social conformity, and a desire for approval from others (Kaufman 2011). People from cultures that operate within the honour/shame code are cognizant that being watched enforces moral rules, "in a shame society, the individual is safe as long as no one knows his misdeed; he can dismiss his misdemeanour from his mind" (Mead 2003, p.494). The concepts of honour and shame are important factors in Arab cultural values, but have been neglected in the academic dishonesty scholarly literature to-date. Our study aimed to bridge these gaps in extant literature by conducting a qualitative analysis of Arab students' perceptions of academic dishonesty in an international university context.

\section{Research Methods}

For our study, we focused on students attending an internationally accredited university in the UAE that follows an American curriculum. The language of instruction is English, as taught by professors from approximately 30 different nationalities. Most of the institutional policies, procedures, and practices have been adopted from USA models of HE, albeit with some adaption to the local context. Essentially, there is a complex cultural melting pot of interactions between students, faculty and the institutional governance structures. This university has students from over 70 different nationalities, mostly from the Arab world, and India and Pakistan. Such student ethnic diversity meant that we expected cultural influences to be important factors in understanding dishonest behaviours at the University. We also wanted to explore the reasons why behaviours were viewed as dishonest in some cultures, but could be considered honourable in others (McCabe, Feghali and Abdallah 2008). This study 
on student attitudes towards academic integrity in the UAE was determined to pose minimal risk to participants and was accepted by the Institutional Review Board of the university concerned.

A qualitative research design was considered the most appropriate for this study because the researchers were exploring students' insights in-depth (Denzin and Lincoln 2005). Our research approach was aided by Myers' view (1997) that the motivation for doing qualitative research, as opposed to quantitative research, comes from the observation that it is our ability to talk about phenomena that leads to others understanding. To this end, we used both in-depth interviews and focus groups, as they can provide a large quantity of rich and illuminating material (Denzin and Lincoln 2005). We also used multiple methods of data collection to enable a richer and more complete understanding of the research issue being examined (Leedy 1993). A multi-method qualitative approach was considered suitable as these different approaches complement each other (Flick 1998; Bryman 1988). In general terms, the strengths of one research method overcome the weaknesses of the other (Deshpande 1983). As well, application of several qualitative techniques generally improves content validity in relatively under-researched areas (Lincoln and Guba 1985). To improve content validity in our study, we triangulated the data collected from interviews, with the data from the focus groups, and contrasted the findings with any published research in the literature.

Participants were invited into the sample from the pool of junior and senior undergraduates in the business school of the chosen university in the UAE. A purposive sampling strategy was used, as the emphasis was on "generating ideas and insights" (Churchill 1995, p. 483). Students were invited to contribute their attitudes to, experiences of, and knowledge about academic dishonesty during an individual interview or through participation in a focus group. They were encouraged to comment openly about academic 
honesty and dishonesty as it related to their own or other students' activities. A deliberate attempt to reduce bias from interviewer/facilitators was made by not giving participants an indication that culture was a particular theme of the study.

In total, there were 14 participants who accepted an invitation for a personal interview by one of these authors. Each of these students had been caught committing an academic dishonesty offence during an exam or assignment, and, after academic sanctions were instigated, each agreed to be interviewed. Participation was voluntary and it was emphasised that interview participation would not change the penalty for academic honesty violations nor grading. The age range of the interview participants was between $20-23$ years old. The students were from a mix of ethnic backgrounds, with the majority from the Arab world including several Saudi, Emirati, Syrian and Jordanian students, plus one student who is Iranian and one from Pakistan.

In addition to the personal interviews, four focus groups were convened with 10-12 participants in each group. These students were not those invited to the personal interviews (by first author), and were invited to join focus groups by the other two authors. Therefore, unlike the individual interviews, the students attending the focus groups had not been caught cheating previously at the university. There was no discrimination for demographic background (age, ethnic background, gender, major or seniority) in the invitation to participate in the focus groups. Instead, the sample was composed of students who broadly represented the multicultural student population at the university and was an open invitation to talk about the issues. These students were asked during the focus group sessions to comment generally about the nature of academic dishonesty at the institution. These students volunteered for the focus groups and understood attendance, or not, would not affect any course grading. 
The qualitative software analysis tool, Nvivo 10, was used for the thematic analysis with all data from the interviews, transcripts of the audio-recordings and field-notes, entered into the software. We followed a "three - phase content analysis procedure", as per McCabe, Trevino and Butterfield (1999, p. 214), and these steps were aided by the software capability. Phase 1 of the analysis was to code descriptively i.e. without interpretation (Miles and Huberman 1994). This phase was achieved by conducting a word frequency query to reveal keywords that could indicate "thought units" of significance to the participants (McCabe, Trevino and Butterfield 1999, p. 214). Phase 2 of the content analysis was a categorisation phase where the context surrounding keywords was explored. In this phase, coding was assigned to data to facilitate the recognition of categories (themes) amongst these data. Phase 3 was a classifying phase for deeper interpretation of the content to enable the identification of emergent patterns or themes (McCabe, Trevino and Butterfield 1999; Miles and Huberman 1994).

All transcripts and field-notes were read and reread by all the researchers at this interpretative stage of the content analysis, to review the "background dynamics" of the content (Miles and Huberman 1994, p. 57). Various research meetings were held amongst these authors to deepen the content analysis through discussion of these dynamics eventually agreement was reached amongst us on themes. Phases 1-3 of the content analysis supported the research objectives revealing evidence of socio-cultural influences on academic honesty and a number of themes emerged.

\section{Results and Discussion}

From our analysis, we identified a number of common themes that have emerged in previous studies (McCabe, Trevino and Butterfield 1999; McCabe and Trevino 1993). For example, students reported that there was too much work given by professors, which 'forced' them to cut corners in assessments by cheating (McCabe and Trevino 1993). Similarly, 
laziness, lack of preparation, and little likelihood of being caught, were all suggested as reasons for some students to be dishonest (McCabe, Feghali and Abdallah 2008). It was also noticeable that most of the participants in this study admitted to some form of cheating in the past, especially at school. All students admitted to being exposed to academic dishonesty in some form, either from cheating first-hand or knowing someone who cheated at the university. While these initial findings are consistent with previous studies, we focus here on the unique socio-cultural influences that emerged in our analysis. We were particularly interested in these deep student insights as they offer a new and interesting contribution towards better understanding of academic dishonesty in this context.

\section{Peer Obligations}

In our data, the theme of "peer obligations" emerged, where Arab students often helped their friends and peers as a mechanism to help them. This derives from the collectivist cultural influences among the Arab students, where it is a social obligation to share work and help class-mates. Some example quotations include:

Three or four times...I let someone cheat off of my examinations.

Cheating at university normally occurs through friendship. If they were friends (Arab or non-Arab friends), I would let them cheat.

Looking at someone else's examination. It is culturally accepted: You look at his paper, you nudge him, and he looks at yours.

Culture is stronger it's more interlinked...like not getting by yourself. If you accept a student here without very good English...then you are at fault and you have to help them through it.

Such behaviour was considered acceptable in this context, irrespective of the official rules of the institution saying that it was unacceptable. Other studies found that peer influence was not a strong driver of dishonest collusion when students were working in groups in a United Kingdom context (Sutton and Taylor 2011). However, because of the collectivist 
nature of this culture, it is not only deemed acceptable to help other students and friends, it is a communal obligation driven by culture (Chapman and Lupton 2004).

Similar peer influence was also evident from focus group data about fellow students not reporting people who cheat. Even though such behaviour breached the academic integrity rules of the university, students were culturally and socially obligated to protect their peers, even though they knew it was wrong:

I would not report someone for cheating. Because it's mean. It's his problem-it's not my problem.

If the action taken against them is very serious, if they're expelled from university, you can feel that you actually ruined their life, their career.

I did not want to rat her out because she's a friend....I don't want to be responsible for ruining people's lives.

The social stigma from reporting incidents was too strong, and acted as a deterrent to reporting others for cheating. This is a common issue in other universities around the world, but the collectivist culture appears to compound the problem and offers new insight to the perception of helping friends.

\section{Patriarchal pressure}

The importance of family in the Arab culture is inter-twined within the collectivism dimension noted earlier (Al Khatib et al. 2005; Hofstede 2001). The family is the centre of Arab culture, and family protection and family honour are very important to an individual Arab, whose responsibility is to maintain the welfare and integrity of the family (Jabeen 2010; Al Khatib et al. 2005). As a patriarchal culture, the Father is often the main person responsible for protecting family honour and building status in the community, and sending children to university enhances the family honour and prestige. This theme emerged strongly in our data. 
Arab parents often push their children towards study at a western-styled university, but such 'pushing' is not only for that institutions' purported superior education. Rather, those mothers and fathers seek the corresponding stature, or esteem that will be conferred by their community upon their daughters and sons for attending a high calibre university. Furthermore, the selection of majors within certain approved professions is strongly encouraged, and historically these include architecture, engineering, finance and medicine. Parents encourage their children to study in these programs because of the conferral of greater prestige upon the family. Such majors will have the potential to confer professional status, the promise of a stable livelihood, and steady income upon the students, and ipso facto confer honour on the family.

The University, and/or major, may not be a students' own choice, and indeed the individual may not want to attend higher education at all. The idea that a young person would not attend university is virtually unthinkable because of the shame it would bring upon her/his family. As a result, the main goal and purpose of attending university is to obtain a degree, which will serve as the gateway to adult life, both personally and professionally. The acquisition of information or knowledge is of secondary importance, and may be negligible in comparison to more highly valued societal aims. The net effect is that, upon graduation, the student will not necessarily have obtained a full western-styled education. Similarly, family expectations are for a high-level education and good grades, which represent the academic standing of their daughter or son, and these in turn reflect on the family status in society. Cheating therefore may be seen as a survival tactic when a student is not competent or willing to study their parents' choice of subject matter. However, family honour will always prevail, as indicated from the quotations of participants below:

I think it's horrible because actually the society have pushed you to do it. Because I am evaluated just by getting this degree; I'm known, I will be honoured just for getting this degree. 
If the society is pushing me to do it, I'll push myself to do whatever society wants. I'm honourable without the degree, but you're actually telling me I'm nothing if I didn't get this.

It's about prestige and title. Even if it comes down to a ludicrous degree.

The attitude of a parent to cheating also appears to affect the students' attitudes, with some participants thinking their parents were not too bothered about them cheating, and whom they considered would think cheating was alright - as long as their daughter/son was not caught.

I cheated in order to not get in trouble with parents.

Personally my parents don't really care about cheating. It's not because I usually don't do it, I only do it for the subjects that struggle in.

So when I do cheat, they know I'm cheating, they just say don't get caught and if I do get caught, they know you're going to suffer the consequences inside you. I mean, they probably did it when they were in school so they'd be hypocrites.

For children born into Arab families, the completion of a university undergraduate program is a social requirement. That situation holds true even if the student is not academically inclined, does not have fully developed reading and writing skills and study habits, or does not wish to work in a field related to her or his course of study. According to Al-Khatib et al. (2005, p.509) "young Arabs are attracted to Western concepts of free enquiry, self-criticism, individual accountability and democracy; all of which are conducive to an individualistic [sic] orientation". However, they lack access to these concepts at school age. Students from schools that follow a western or international education therefore continue to excel against students from Arabic curriculum schools in terms of analytical and critical thinking skills, independent thought, and creativity. Students from Arabic speaking schools then are more prone to academic dishonesty in order to mitigate their different school backgrounds, and keep up with their peers from international schools.

\section{Shame avoidance}


Another theme that emerged in our data was the student perceptions towards shame avoidance. As noted earlier, students reported strong obligations to their family, and we also found that the concepts of status, honour and collectivism, are closely linked to "shame" avoidance in Arab society. In a society with clear social strictures, obligations, and rules of conformity, the ability of an individual to assert her or his autonomy in the face of authority is crucial and valuable. Outward appearances (even if ultimately false) are maintained in order to obtain the necessary approval for the family to avoid shame by covering up misdeeds (Kaufman 2011; Mead 2003). Interestingly, students who were caught cheating, saw such indiscretions as temporary, and therefore the initial guilt disappeared (Wikan, 1984).

There is no guilt, if I don't get caught.

I've never been in such situation, but I believe that I won't feel guilty but maybe ashamed of myself if I got caught.

There is no feeling of guilt, the last thing they think about after four years of stress, when you see your parents happy, you're blind to everything else.

Because usually shame goes with you for the rest of your life, but guilt is like its other than it's momentarily it goes on.

If I or anyone studies really hard, he's honest, he doesn't cheat, but he doesn't pass and he doesn't get a degree, no one's going to be proud of him for being honest.

The pride from being awarded the degree certificate in front of family members at graduation also brings that family a certain degree of respect and honour among their social peers. Achievement of this graduation honour by cheating does not matter, as long as the student does not get caught and bring shame on the family. In effect, the ends justify the means.

Arab societies are constructed around very clear and rigid communal obligations, and to oppose familial obligations would be to risk ostracism from all social support networks. An individual Arab will avoid bringing shame or embarrassment upon the clan, family or tribe members through the individual's adherence to social conformity (Kaufman 2011). Attending 
university and obtaining a degree can therefore shield the family from any corresponding shame, before other members of the community, for failure to meet obligations of the family or society at large. Participants in our study demonstrated the worry of bringing shame on the family, reinforcing the findings of Jabeen (2010) and Al Khatib et al. (2005) who also highlighted the importance of shame avoidance in the Arab culture.

\section{Fahlawi mind-set}

One of the most interesting themes that emerged from our data was the student perceptions of a Fahlawi mindset among Arab students. Linked with Arab cultural notions of honour and shame is the notion of Fahlawi - a word derived from Farsi that connotes a clever or quick-witted individual. In Arabic, the popular cultural term 'Fahlawi' refers to a person with a highly adaptive attitude (Moughrabi 1978) who has (or is perceived to have) the ability to achieve things with minimal effort (Mayfield 2014; Beit-Hallahmi 1972). According to the various authors who have written on this matter, the Fahlawi personality is typified by shortcuts in place of hard work to achieve the expected results - demonstrating shrewdness and an independent spirit. As the Fahlawi may be preoccupied with avoiding hard work and effort, cheating often becomes almost inevitable in accomplishing a task (Falk 1992). The vast majority of the students that were interviewed stated they studied no more than a few hours a week and many could not even meet this level of study. Western students (with native fluency in English) would also find it difficult to do well or even pass classes in which they exhibited this limited amount of studiousness. For students in a Western-style university, who may be attempting to overcome deficits in English proficiency, the Fahlawi saw cheating as a necessity in light of the efforts invested in reading or comprehending course material.

It is important to note that this personality is not immediately viewed in negative terms, but is seen by many as a necessary force in the face of a restrictive society. Consistent with other tenets of a shame culture, the Fahlawi focuses on impressions and perceptions, and he 
or she is more concerned with accomplishing tasks, rather than how such tasks were accomplished (Mayfield 2014). The Fahlawi is not interested in the meticulous diligence, which must be implemented to achieve a goal, but is more interested in not being viewed by others as incapable or incompetent (Dessouki 1973, p.190). In a perverse way, other peer students admired the Fahlawi who was cheating, as the cheater gained 'respect' from getting one over the system and the professor:

Some students who cheat and get away with it gain a lot more peer respect, and peer recognition.

Personally I think I'm happy for his talent, I'm upset because I don't have this talent.

But maybe, he seems like he's a person that doesn't study but he got a higher grade than me, he's just smart.

An anecdotal story also emerged where a professor caught a student cheating, and failed him from the course as a result of that incident. The next week, the best friend of this student was caught cheating by the same professor, and the professor sanctioned this student accordingly. In contrast, this infraction did not warrant dismissal from the class. The second student's response was "you shamed [my friend], but I am not going to let you shame me," and after a protracted series of negotiations and appeals, their Fahlawi attitudes prevailed, and prevented their dismissal from the course for a similar offense. The student was incapable of taking ownership over his actions, but blamed the professor for not respecting the framework of shame. Once the Fahlawi is called to task, he or she becomes focused on removing responsibility from him or herself and transferring it elsewhere (Moughrabi 1978). The Fahlawi finds it nearly impossible to be accountable for his or her actions - which is wholly consistent with the shame dynamic noted earlier.

\section{Conclusions and recommendations}


We have found through our study that a number of socio-cultural themes have emerged which may lead towards a propensity towards academic dishonesty amongst Arab students. Family influences were found to be very important. A student will justify cheating based upon the need to obtain a university degree acceptable to her/his family and society. The student does not feel any negative impact on the value of the degree obtained because the objective is graduation from university. The value of cheating does not outweigh any moral implications related to cheating, nor does the student view cheating as a personal affront to professor or university. Furthermore, such a student will downplay the meaning of cheating. In the mind of this student, cheating is not a matter of major importance, especially since she/he may not have experienced any severe consequences to cheating in their prior education.

Peer obligations were important. Arab cultural values dictate that confrontation is to be avoided in situations where one person wins and another person loses, for the primary reason that the loser is shamed in front of her/his family and community (Wikan 1984). As a result, academic discipline is not strongly instilled in that system, and violations of academic honesty are marginalised. Because of this prior educational culture, it is not uncommon for these students to lack a moral conscience or culpability with respect to their academic behaviour in higher education. Shame avoidance appears to be important in this socio-cultural context, including the character of the Fahlawi who was much admired for ability to avoid shame and work (Kaufman 2011; Mead 2003).

Our concern was that universities that internationalise have not fully appreciated the influence of socio-cultural factors when exporting their models of education to other countries. Many US business schools have focused on building a more international profile and have exported their curriculum, and its respective policies and procedures, to countries such as China, Malaysia and the UAE (McCabe, Feghali and Abdallah 2008). These have 
been successful as the brand equity of US higher education is strong. Such universities have set up satellite campuses around the world, or developed partnerships with local education providers, to drive their international agenda and export their educational products. Most leading academic institutions promote the highest ethical and rigorous standards as one of the primary determinants of their academic reputations. The question of raising the bar on education in the Arab World, and specifically in the Arab Gulf states, may not be adequately addressed simply by the introduction of universities with western curricula (McCabe, Trevino and Butterfield 1999).

Our qualitative analysis of Arab students' perceptions of academic dishonesty at a university in the Middle-East has opened up a number of issues that future researchers into academic dishonesty should try to address through more empirical studies. The influence of culture appears to be a strong determinant of academic dishonesty among Arab students. Central to this empirical research will be the need to understand the cultural influences that cause Arab students to be dishonest, and to implement policies and procedures that inhibit such behaviours. A recommendation to personnel of international universities is to thoroughly explore the socio-cultural influences within a region for guidance on cultural sensitivity. Then current policies can be updated and strengthened to preserve academic integrity as an element of exporting their educational models. 


\section{References}

Abou-Zeid, M.N. 2016. Academic Integrity: A perspective from Egypt. In Bretag Ed. 2016. Handbook of Academic Integrity: 135-145. Springer, Singapore.

Ahlawat, S. S., and Ahlawat, S. 2006. Competing in the global knowledge economy: Implications for business education. Journal Of American Academy Of Business, 81, 101-105.

Al-Khatib, J.A., Vitell, S.J., Rexeisen, R., and Rawwas, M. 2005. Inter-country differences of consumer ethics in Arab countries. International Business Review, 144: 495-516.

Alt, D., and Geiger, B. 2012. Goal orientations and tendency to neutralize academic cheating: An ecological perspective. Psychological Studies, 574: 404-416.

Ashworth, P., Bannister, P. and Thorne, P. 1997. Guilty in whose eyes? University students' perceptions of cheating and plagiarism in academic work and assessment. Studies in Higher Education, 222: 187-203.

Beasley, E. 2010, March. Social norms and academic dishonesty. East Lansing: Michigan State University. Retrieved from http://gradworks.umi.com/14/78/1478816.html

Beit-Hallahmi, B. 1972. Some psychosocial and cultural factors in the Arab-Israeli conflict: A review of the literature. Journal of Conflict Resolution, 162: 269-280.

Bretag, T., Harper, R., Burton, M., Ellis, C., Newton, P., Rozenberg, P., Saddiqui, S. and van Haeringen. 2018. Contract cheating: a survey of Australian university students, Studies in Higher Education, DOI: 10.1080/03075079.2018.1462788.

Bretag T. 2016. Defining Academic Integrity: International Perspectives - Introduction. In Bretag Ed. 2016. Handbook of Academic Integrity: 1-3. Springer, Singapore.

Brown, B. S., and Choong, P. 2005. An investigation of academic dishonesty among business students at public and private United States universities. International Journal of Management, 222: 210-214.

Bryman, A 1988. Quantity and quality in social research. London: Routledge.

Buckner, Elizabeth, and Hodges, Rebecca. 2016. Cheating or Cheated? Surviving Secondary Exit Exams in a Neoliberal Era. Compare: A Journal of Comparative and International Education: 1-21.

Carrell, S.E., Malmstrom, F.V., and West, J.E. 2008. Peer effects in academic cheating. Journal of Human Resources. 431: 173-20.

Carroll, J. 2007. A handbook for deterring plagiarism in higher education. Oxford: Oxford Centre for Staff and Learning Development.

Chapman, K. and Lupton, R. 2004. Academic dishonesty in a global educational market: a comparison of Hong Kong and American university business students. The International Journal of Educational Management. 187: 425-435. 
Churchill, G.A., Jr. 1995. Marketing research: Methodological foundations. 6th Edition. New York: The Dryden Press.

Cinali, G. 2016 Middle Eastern Perspectives of Academic Integrity: A View from the Gulf Region In Bretag Ed. 2016 Handbook of Academic Integrity: 113-133. Springer, Singapore.

Creighton, M.R. 1990. Revisiting shame and guilt cultures: A forty-year pilgrimage. Ethos, 183: 279-307.

Denzin, N.K. and Lincoln, Y.S. 2005. Introduction: The discipline and practice of qualitative research. In N.K. Denzin and Y.S. Lincoln Eds. The handbook of qualitative research. Sage: California.

Deshpande, R. 1983. Paradigms lost: on theory and method in research in marketing. Journal of Marketing, 47, Fall: 101-110.

Dessouki, A.E.H. 1973. Arab intellectuals and Al-Nakba: The search for fundamentalism. Middle Eastern Studies, 92: 187-195.

Diekhoff, G.M., LaBeff, E.E., Shinohara, K., and Yasukawa. H. 1999. College cheating in Japan and the United States. Research in Higher Education. 403: 343-353.

Ercegovac, Z., and Richardson, J. (2004). Academic Dishonesty, plagiarism included, in the Digital Age: A Literature Review. College \& Research Libraries, 65: 301-318.

Falk, A. 1992. Unconscious aspects of the Arab-Israeli conflict. The psychoanalytic study of society, 17: 213-247.

Flick, U. 1998. An introduction to qualitative research. London: Sage.

Grimes, P. W. 2004. Dishonesty in academic and business: A cross-cultural evaluation of student attitudes. Journal of Business Ethics, 492: 273-290.

Gullifer, M. J., and Tyson, A. G. 2014. Who has read the policy on plagiarism? Unpacking students' understanding of plagiarism. Studies in Higher Education, 397: 1202-1218

Hofstede, G. 2001. Culture's consequences: Comparing values, behaviours, institutions, and organizations across nations. Thousand Oaks, CA: Sage.

Ives, R., Alama M., Mosora, L.C., Radulescu, L.G. and Clinci, A.I. 2017. Patterns and predictors of academic dishonesty in Romanian university students. Higher Education. November 2017, 74: 815-831.

Jabeen, F. 2010. Attitudes towards career women roles in outlook of family-social surroundings: Perspectives from the UAE. The Business Review, 162: 209-215. 
James, M.X., Miller, G.J. and Wyckoff, T.W. 2017. Comprehending the cultural causes of English writing plagiarism in Chinese students at a western-style university. Journal of Business Ethics, 1-12. https://doi.org/10.1007/s10551-017-3441-6.

Kaufman, W. 2011. Understanding honour: Beyond the shame/guilt dichotomy. Social Theory and Practice, 374: 557-573.

Khan, Z.R and S. Balasubramanian. 2012. Students go click, flick and cheat... e-cheating, technologies and more. Journal of Academic and Business Ethics 6: 1

Kwong, T., H.-M. Ng, K.-P. Mark, and E. Wong. 2010. Students' and Faculty's Perception of Academic Integrity in Hong Kong. Campus-Wide Information Systems. 275: 341-355.

Lawson, R. 2004. Is classroom cheating related to business students' propensity to cheat in the 'real world'? Journal of Business Ethics, 492: 189-199.

Leedy, P. 1993. Practical research: planning and design, fifth edition. New York: Macmillan Publishing Company.

Lincoln, Y.S., and Guba, E.G. 1985. Naturalistic inquiry. Newbury Park, CA: Sage Publications.

Magnus, J.R., Polterovich, V.M., Danilov, D.L., and Savvateev. A.V. 2002. Tolerance of cheating: an analysis across countries. Journal of Economic Education, 33, Spring, $125-135$.

Mayfield, James, B. 2014. Rural Politics in Nasser's Egypt: A quest for legitimacy. University of Texas Press: Austin, TX.

McCabe, D., Feghali, T., and Abdallah, H. 2008. Academic dishonesty in the Middle East: Individual and contextual factors. Research in Higher Education, 495: 451 - 467.

McCabe, D.L., Trevino, L.K. and Butterfield, K.D. 2002. Honour codes and other contextual influences on academic integrity: A replication and extension of modified honour code settings. Research in Higher Education, 433: 357-378.

McCabe, D.L., Trevino, L.K. and Butterfield, K.D. 1999. Academic Integrity in honour code and non-honour code environments a qualitative investigation. The Journal of Higher Education, 702: 211-234.

McCabe, D. L. and Trevino, L.K. 1997. Individual and contextual influences on academic dishonesty. Research in Higher Education, 383: 379-396.

McCabe, D. L. and Trevino, L.K. 1993. Academic dishonesty: Honour codes and other contextual influences. Journal of Higher Education, 645: 520-538.

Macfarlane, B., Zhang, J. and Pun, A. 2014. Academic integrity: A review of the literature. Studies in Higher Education, 39:2, 339-358. 
McCrohon, M., and Nyland, B. 2018. The perceptions of commoditisation and internationalisation of higher education in Australia: An interview study of Chinese international students and their lecturers. Asia Pacific Education Review, 19:1, 17-26. doi:10.1007/s12564-018-9515-Z

McCrohon, M., and Nyland, B. 2016. Academic experiences in teaching Chinese international students. Journal of Applied Research in Higher Education, 8:2, 238-251. doi:10.1108/JARHE-11-2014-0106

Mead, M. Ed., 2003. reprinted. Cooperation and competition among primitive peoples, New York: McGraw-Hill.

Metwally, D. 2013. Academic cheating in Egyptian Universities. 2013. The Journal of Educational and Societal Research, 37: 588-601.

Miles, M.B., and Huberman, M. 1994. Qualitative data analysis. 2nd ed. London: SAGE.

Moffatt, M. 1990. Undergraduate cheating. ERIC Document No. 334931.

Moughrabi, F. M. 1978. The Arab basic personality: A critical survey of the literature. International Journal of Middle East Studies, 91: 99-112.

Myers M D. 1997. Qualitative research in information systems. MIS Quarterly, June: 241242.

Nonis, S., and Swift, C.O. 2001. An examination of the relationship between academic dishonesty and workplace dishonesty: A multi-campus investigation. Journal of Education for Business, 772: 69-77.

Park, C. 2003. In other words: Plagiarism by university students - Literature and lessons. Assessment and Evaluation in Higher Education, 285: 471-489.

Payan, J., Reardon, J. and McCorkle, D.E. 2010. The effect of culture on the academic honesty of marketing and business students. Journal of Marketing Education, 323: 275291.

Rehman, R. R. and Waheed, A. 2014. "Ethical perception of university students about academic dishonesty in Pakistan: Identification of student's dishonest acts". The Qualitative Report, 19. Accessed October 4, 2018 https://nsuworks.nova.edu/tqr/vol19/iss4/1/

Ralston, D.A., Giacalone, A.R., and R.H. Terpstra. 1994. Ethical perception of organizational politics: a comparative evaluation of American and Hong Kong managers. Journal of Business Ethics, 1312: 989-999.

Rawlinson, D. R., and Lupton, R.A. 2007. Cross-national attitudes and perceptions concerning software piracy: A comparative study of students from the United States and China. Journal of Education for Business, 832: 87-94. 
Rawwas, M.Y.A., Al-Khatib, J.A., and Vitell, S. 2004. Academic dishonesty: A Crosscultural comparison of U.S. and Chinese marketing students. Journal of Marketing Education, 261: 89-100.

Shaw, K.E. 1996. Cultural issues in evaluation studies of Middle East higher education. Assessment and Evaluation in Higher Education, 214: 313-325.

Simkin, M.G., and McLeod, A. 2009. Why do college students cheat? Journal of Business Ethics, 943: 441-445.

Sutton, A., and Taylor, D. 2011. Confusion about collusion: working together and academic integrity. Assessment and Evaluation in Higher Education, 367: 831-841.

Szabo, A., and Underwood, J. 2004. Cybercheats: Is information and communication technology fueling academic dishonesty? Active Learning in Higher Education, 52: 180-200.

Teixeira, A. and Rocha, M. 2008. Academic cheating in Spain and Portugal: an empirical explanation. International Journal of Iberian Studies, 21: 3-22.

Tsui, A. P., and Ngo, H. 2016. Social-motivational factors affecting business students cheating behavior in Hong Kong and China. Journal of Education for Business, 91:7, 365-37.

UNESCO, 2003. "Combating academic fraud towards a culture of integrity towards a culture of integrity". International Institute for Educational Planning. Accessed October 4, 2018 http://unesdoc.unesco.org/images/0013/001330/133038e.pdf

Vandehey, M., Diekhoff, G., and LaBeff, E. 2007. College cheating: A twenty-year follow-up and the addition of an honor code. Journal of College Student Development, 484: 468480

Wikan, U. 1984. Shame and honour: A contestable pair. Man: New Series, 194: 635-652.

Williams, S., Tanner, M., Beard, J., and Chacko, J. 2014. Academic misconduct among business students: a comparison of the US and UAE. Journal of Academic Ethics, 121: $65-73$. 